\title{
Sex differences in TGFB- $\beta$ signaling with respect to age of onset and cognitive functioning in schizophrenia
}

\author{
Dorota Frydecka' \\ Błażej Misiak ${ }^{1,2}$ \\ Edyta Pawlak-Adamska ${ }^{3}$ \\ Lidia Karabon ${ }^{3,4}$ \\ Anna Tomkiewicz ${ }^{3}$ \\ Paweł Sedlaczek ${ }^{5}$ \\ Andrzej Kiejna \\ Jan Aleksander Beszłej ${ }^{\prime}$ \\ 'Department of Psychiatry, Wroclaw \\ Medical University, Wroclaw, \\ Poland; ${ }^{2}$ Department of Genetics, \\ Wroclaw Medical University, \\ Wroclaw, Poland; ${ }^{3}$ Laboratory of \\ Immunopathology, Department \\ of Experimental Therapy, Institute \\ of Immunology and Experimental \\ Therapy, Polish Academy of Sciences, \\ Wroclaw, Poland; ${ }^{4}$ Department of \\ Clinical Urology, Wroclaw Medical \\ University, Wroclaw, Poland; ${ }^{5}$ Ist \\ Department and Clinic of Gynecology \\ and Obstetrics, Wroclaw Medical \\ University, Wroclaw, Poland
}

This article was published in the following Dove Press journal:

Neuropsychiatric Disease and Treatment

5 March 2015

Number of times this article has been viewed

\begin{abstract}
There are studies showing that gene polymorphisms within the transforming growth factor- $\beta$ (TGF- $\beta$ ) signaling constitute schizophrenia risk variants. However, the association between TGFB1 gene polymorphisms (+869T/C and +915G/C), TGF- $\beta$ level with schizophrenia course, and its symptomatology together with cognitive functioning has not been investigated so far. We included 151 patients with schizophrenia and 279 healthy controls. Cognitive functioning was assessed using Rey Auditory Verbal Learning Test, Trail Making Test (TMT)-A and TMT-B, Verbal Fluency task, Stroop test, as well as selected subtests from the Wechsler Adults Intelligence Scale - Revised, Polish adaptation (WAIS-R-P1): Digit Symbol Coding, Digit Span Forward and Backward, and Similarities. Additionally, serum TGF- $\beta$ levels were measured in 88 schizophrenia patients and 88 healthy controls. Serum TGF- $\beta$ level was significantly higher among patients with schizophrenia in comparison with healthy controls; however, the studied polymorphisms were not associated with TGF- $\beta$ level in schizophrenia patients. Subjects carrying the $+869 \mathrm{~T}$ allele performed significantly worse in comparison with $+869 \mathrm{CC}$ homozygotes on Stroop task, Verbal Fluency task and Digit Symbol Coding task. There was a significant difference in age of psychosis onset in female schizophrenia patients with respect to the TGFB1 $+869 \mathrm{~T} / \mathrm{C}$ polymorphism. Additionally, adjustment for possible confounders revealed that there was a significant difference in cognitive performance on Digit Symbol Coding task with respect to the $T G F B 1+869 \mathrm{~T} / \mathrm{C}$ polymorphism among female schizophrenia patients. Our results suggest that TGF- $\beta$ signaling might be a valid link contributing to observed differences in age of onset and the level of cognitive decline between male and female schizophrenia patients.
\end{abstract}

Keywords: cognition, digit symbol coding task, gender differences, gene polymorphism, TGF, transforming growth factor-beta

\section{Introduction}

Cytokine alterations are increasingly recognized as part of schizophrenia pathophysiology. ${ }^{1-3}$ Some cytokines including interleukin (IL)-12, interferon- $\gamma($ IFN- $\gamma$ ), and tumor necrosis factor- $\alpha$ (TNF- $\alpha$ ) serve as trait markers of schizophrenia as they are increased in patients with first-episode psychosis and acute relapse, and during symptomatic stability. Other cytokines, including IL-1 $\beta$, IL-6, and transforming growth factor- $\beta$ (TGF- $\beta$ ) appear to be state markers, which are increased during acute relapses in comparison with periods of symptomatic stability. ${ }^{4}$

TGF- $\beta$ is a regulatory cytokine that influences proliferation, differentiation, and

Correspondence: Dorota Frydecka Department of Psychiatry, Wroclaw Medical University, 10 Pasteur Street, 50-367 Wroclaw, Poland

Tel +48 7I 784 I6 I6

Fax +48 7I $784 \quad 1602$

Email dfrydecka@gmail.com survival of lymphocytes, natural killer cells, dendritic cells, macrophages, mast cells, and granulocytes. ${ }^{5}$ Interestingly, TGF- $\beta$ has been found to regulate differentiation and survival of midbrain dopaminergic neurons. ${ }^{6-8}$ The recent genome-wide association studies data analysis revealed that TGF- $\beta$ signaling is one of the top ranked pathways 
associated with schizophrenia. ${ }^{9}$ In addition, overexpression of the ZNF804A gene, which is a susceptibility gene for schizophrenia supported by genome-wide association studies data, has been found to upregulate genes implicated in the TGF- $\beta$ signaling. ${ }^{10}$ There is also one postmortem study showing that the TGF- $\beta$ signaling pathway genes are upregulated within hippocampal cells in schizophrenia patients. ${ }^{11}$

The TGF- $\beta$ gene (TGFB1) has biallelic single nucleotide polymorphisms (SNPs) at codon 10 (position +869$)$ and at codon 25 (position +915), both causing amino acid substitutions and both known to influence alterations in TGF- $\beta$ synthesis. ${ }^{12,13}$ Our investigation of these SNPs showed that the $T G F B 1+869 \mathrm{~T} / \mathrm{C}$ polymorphism is associated with schizophrenia susceptibility. ${ }^{14}$ The risk of schizophrenia was more than twofold higher in carriers of the T allele (TT and TC genotypes) in comparison with patients with the $\mathrm{CC}$ genotype. Interestingly, when we analysed sex differences, this association was significant in females, while in males it showed a trend towards statistical significance, suggesting the influence of sex differences on the TGF- $\beta$ signaling.

Emerging evidence indicates that genetic factors influencing the TGF- $\beta$ signaling may be associated with cognitive deficits. Loeys et $\mathrm{al}^{15}$ identified heterozygous mutations in genes encoding TGF- $\beta$ receptors (TGFBR1 and TGFBR2) that underlie the development of the syndrome of cardiovascular, craniofacial, neurocognitive, and skeletal disturbances. Furthermore, transgenic mice models overexpressing TGF- $\beta$ are characterized by cognitive deficits mimicking those specific for Alzheimer's disease. ${ }^{16,17}$ Finally, there is one study showing the association between the $T G F B 1+869 \mathrm{~T} / \mathrm{C}$ polymorphism and the risk of Alzheimer's disease. ${ }^{18}$ However, there are no studies addressing the influence of the TGF- $\beta$ signaling on cognitive functioning in schizophrenia.

The aim of this study was to investigate whether polymorphisms in the TGFB1 gene $(+869 \mathrm{~T} / \mathrm{C}$ and $+915 \mathrm{G} / \mathrm{C})$ or serum TGF- $\beta$ level are associated with clinical manifestation, course of the disorder, and cognitive performance in schizophrenia.

\section{Material and methods Subjects}

We recruited 279 controls (61 females and 196 males of mean age $38.7 \pm 8.8$ years), and 158 patients with schizophrenia (89 females and 69 males of mean age 38.0 \pm 11.9 years) including individuals recovered from acute relapse and stable outpatients. ${ }^{14}$ All participants were Caucasians and came from the same geographic area - Lower Silesia. The study was approved by the Ethics Committee at Wroclaw
Medical University and all subjects gave informed consent. The study was performed in accordance with the 1964 Declaration of Helsinki and its later amendments. Participants were excluded on the basis of the following criteria: history of traumatic brain injury, neurologic disorders, severe physical health impairments, and comorbid substance use disorders with the exception of nicotine. Additionally, they had no current infections, allergies, nor present and past history of autoimmune disorders. Present, past, and family history of psychiatric illness was negative in all control subjects.

Genotyping of the TGFB1 polymorphisms (+869T/C and $+915 \mathrm{G} / \mathrm{C}$ ) was performed in all participants according to the methodology described in our previous article, ${ }^{14}$ while serum TGF- $\beta$ level was assessed in the randomly selected group of 88 schizophrenia subjects and 88 healthy controls matched for sex, age and genotype distribution.

\section{Assessment of psychopathology and cognitive functions}

A diagnosis of schizophrenia was based on Diagnostic and Statistical Manual of Mental Disorders IV criteria and established by the same two senior board psychiatrists. Lifetime psychopathology and course of schizophrenia were assessed using the Operational Criteria for Psychotic Illness (OPCRIT) checklist. ${ }^{19}$ In turn, psychopathology on the day of assessment was evaluated using the Positive and Negative Syndrome Scale (PANSS), ${ }^{20}$ the Scale for Assessment of Positive Symptoms (SAPS), ${ }^{21}$ and the Scale for Assessment of Negative Symptoms (SANS). ${ }^{22}$ Assessment of cognitive performance was performed in schizophrenia patients using the following tests: Rey Auditory Verbal Learning Test, ${ }^{23}$ Trail Making Test (TMT-A, TMT-B), ${ }^{24}$ verbal fluency tests (F, A, and S letters, ${ }^{25}$ and supermarket), ${ }^{26}$ Stroop test, ${ }^{27}$ as well as selected Wechsler Adults Intelligence Scale - Revised, Polish adaptation (WAIS-R-P1) subtests (Digit Symbol Coding Test, Digit Span Forward and Backward, and Similarities). ${ }^{28}$

\section{Genotyping}

Genomic DNA was obtained from peripheral blood leukocytes (from whole frozen blood) using the QIAamp DNA Blood Mini Kit (Qiagen NV, Venlo, the Netherlands). The $T G F B 1+869 \mathrm{~T} / \mathrm{C}(\mathrm{rs} 1800470, \mathrm{c} .29 \mathrm{C}>\mathrm{T})$ and the TGFB1 $+915 \mathrm{G} / \mathrm{C}(\mathrm{rs} 1800471$, c.74G $>\mathrm{C}$ ) polymorphisms were examined by the polymerase chain reaction (PCP) with sequence specific primers technique (single specific primer-PCR) using the PCYTGEN kit (One Lambda, Canoga Park, CA, USA). The PCR products were visualized on $2 \%$ agarose gel. 


\section{TGF- $\beta$ measurement}

Serum samples were stored in aliquots at $-80^{\circ} \mathrm{C}$. Serum concentrations were measured blinded for case and control status. Serum hs-CRP was measured with use of the C-reactive protein extended range method on the Dimension ${ }^{\circledR}$ clinical chemistry system (Siemens Healthcare Diagnostics Inc., Newark, NJ, USA). Serum levels of TGF- $\beta$ were measured using a commercially available Human TGF- $\beta$ Immunoassay (Quantikine ${ }^{\circledR}$ ELISA; R\&D Systems, Inc., Minneapolis, MN, USA), according to the manufacturer's instructions.

\section{Statistics}

The differences in serum levels of TGF- $\beta$ between subjects with different $T G F B 1+869 \mathrm{~T} / \mathrm{C}$ and $+915 \mathrm{G} / \mathrm{C}$ genotypes, as well as different allele carriers in both schizophrenia patients and healthy controls, were compared using Kruskal-Wallis test and Mann-Whitney $U$-test. The analysis of covariance was performed to control for age and sex. Demographic and clinical data with respect to the $T G F B 1+869 \mathrm{~T} / \mathrm{C}$ polymorphism among patients with schizophrenia were compared using Kruskal-Wallis test (body mass index [BMI], age, pack-year smoking index, chlorpromazine equivalent, years of education, disease duration, number of previous episodes) and $\chi^{2}$ test (sex, education, family history of schizophrenia, course of the disorder). Kaplan-Meier survival analysis was used to assess the difference in the age of psychosis onset between subjects with different TGFB1 +869T/C and $+915 \mathrm{G} / \mathrm{C}$ genotypes. Differences between two survival curves were tested with log-rank test. Cognitive performance and psychopathological manifestation with respect to the $T G F B 1+869 \mathrm{~T} / \mathrm{C}$ and $+915 \mathrm{G} / \mathrm{C}$ were compared using Kruskal-Wallis test and Mann-Whitney $U$-test. Correlations between clinical variables and cognitive functioning with serum TGF- $\beta$ level were assessed using Spearman's rank correlations (Spearman's rho). The association between the TGFB1 polymorphisms and TGF- $\beta$ serum level with cognitive functioning was performed using linear regression analysis adjusting for age, education level, illness duration,

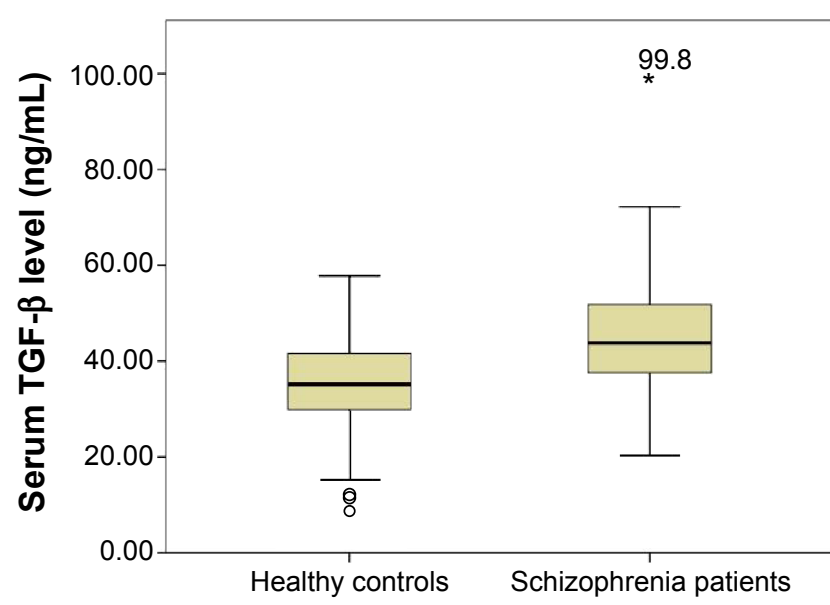

Figure I Serum TGF- $\beta$ levels in healthy control subjects and patients with schizophrenia $(P<0.000 \mathrm{I})$.

total PANSS score, BMI, smoking, and chlorpromazine equivalent. Differences were considered as statistically significant if the two-tailed $P$-value was less than 0.05 . All analyses were performed using the Statistical Package for Social Sciences version 20.

\section{Results}

Serum TGF- $\beta$ levels were significantly higher in schizophrenia patients in comparison with healthy controls (median \pm interquartile range: $43.56 \pm 13.36 \mathrm{ng} / \mathrm{mL}$ and $35.15 \pm 11.83 \mathrm{ng} / \mathrm{mL}$, respectively, $P<0.0001$ ) (Figure 1). This difference was still statistically significant after covarying for age and sex of the participants $(F=25.28, P<0.0001)$.

All results for patients and controls were in Hardy-Weinberg equilibrium $(P>0.05)$. The association of the TGFB1 polymorphisms with serum TGF- $\beta$ level are presented in Tables 1 and 2. With respect to the TGFB1 $+869 \mathrm{~T} / \mathrm{C}$ polymorphism, healthy controls with $\mathrm{CT}$ and $\mathrm{CC}$ genotypes were characterized by higher levels of serum TGF- $\beta$ in comparison with subjects with TT genotype $(P=0.005)$ (Table 1$)$. There was no significant association between the $T G F B 1+869 \mathrm{~T} / \mathrm{C}$ polymorphism and TGF- $\beta$ level in schizophrenia patients. With respect to

Table I The comparison of TGF- $\beta$ levels between schizophrenia patients and healthy controls with respect to distinct genotypes and alleles' carriers of the TGFBI $+869 \mathrm{~T} / \mathrm{C}$ polymorphism

\begin{tabular}{|c|c|c|c|c|c|c|c|}
\hline \multirow[t]{2}{*}{ Study group } & \multicolumn{3}{|c|}{ TGFB I +869T/C genotype } & \multirow[t]{2}{*}{$P$-value ${ }^{a}$} & \multicolumn{2}{|c|}{ TGFBI $+869 \mathrm{~T} / \mathrm{C}$ allele carriers } & \multirow[t]{2}{*}{$P$-value } \\
\hline & $\overline{C C}$ & CT & TT & & CC & CT and TT & \\
\hline $\mathrm{SCH}$ & $43.26(12.26)(n=2 I)$ & $42.62(15.00)(n=36)$ & $44.47(13.94)(n=31)$ & 0.84 & $43.26(I 2.26)(n=2 I)$ & $44.09(14.54)(n=67)$ & 0.79 \\
\hline $\mathrm{HC}$ & $38.84(13.22)(n=14)$ & $37.22(\mid 3.06)(n=45)$ & $30.31(13.88)(n=29)$ & 0.005 & $38.84(\mid 3.22)(n=\mid 4)$ & $34.5 \mathrm{I}(13.07)(\mathrm{n}=74)$ & 0.09 \\
\hline
\end{tabular}

Notes: aKruskal-Wallis test; ${ }^{b}$ Mann-Whitney U-test. Median values and interquartile range of TGF- $\beta$ levels are presented (ng/mL). Significant association has been marked in bold characters ( $P$-value $<0.05$, two-tailed).

Abbreviations: $\mathrm{HC}$, healthy control subjects; $\mathrm{SCH}$, schizophrenia patients. 
Table 2 The comparison of TGF- $\beta$ levels between schizophrenia patients and healthy controls with respect to distinct genotypes and alleles' carriers of the TGFBI $+915 \mathrm{G} / \mathrm{C}$ polymorphism

\begin{tabular}{|c|c|c|c|c|c|c|c|}
\hline \multirow[t]{2}{*}{ Study group } & \multicolumn{3}{|c|}{ TGFB I +9 I5G/C genotype } & \multirow[t]{2}{*}{$P$-value ${ }^{a}$} & \multicolumn{2}{|c|}{ TGFBI +9 I5G/C allele carriers } & \multirow[t]{2}{*}{$P$-value ${ }^{b}$} \\
\hline & CC & CG & GG & & CC and CG & GG & \\
\hline $\mathrm{SCH}$ & $N A(n=I)$ & $38.25(14.13)(n=14)$ & $44.15(13.71)(n=72)$ & 0.31 & $38.36(12.42)(n=15)$ & $44.15(13.7 \mid)(n=70)$ & 0.12 \\
\hline $\mathrm{HC}$ & $\mathrm{NA}(\mathrm{n}=0)$ & $32.60(10.47)(n=12)$ & $35.87(13.23)(n=76)$ & 0.18 & $32.60(10.47)(n=12)$ & $35.87(\mid 3.23)(n=76)$ & 0.18 \\
\hline
\end{tabular}

Notes: ${ }^{a}$ Kruskal-Wallis test; ${ }^{b}$ Mann-Whitney $U$-test. Median values and interquartile range of TGF- $\beta$ levels are presented (ng/mL).

Abbreviations: $\mathrm{HC}$, healthy control subjects; NA, not applicable; $\mathrm{SCH}$, schizophrenia patients.

the $T G F B 1+915 \mathrm{G} / \mathrm{C}$ polymorphism, there was no significant association with serum TGF- $\beta$ either in schizophrenia patients or in healthy controls $(P>0.05)$ (Table 2$)$.

There was no association between the TGFB1 $+869 \mathrm{~T} / \mathrm{C}$ nor $+915 \mathrm{G} / \mathrm{C}$ polymorphisms with domains evaluated by the OPCRIT checklist such as: disturbances related to speech and form of thought; affect and associated features; appearance and behavior; as well as abnormal beliefs and abnormal perceptions (data not shown). However, there was a significant difference in age of psychosis onset between schizophrenia patients with distinct $T G F B 1+869 \mathrm{~T} / \mathrm{C}$ polymorphism genotypes (log-rank test $\chi^{2}=6.54, P=0.038$ ) (Figure 2). When the patients were divided with respect to sex, there was still a significant association in females (log-rank test $\chi^{2}=9.27, d f=2, P=0.01$ ) but not in males (log-rank test $\left.\chi^{2}=0.57, d f=2, P=0.75\right)$. With respect to the $T G F B 1+915 \mathrm{G} / \mathrm{C}$ polymorphism, there were no significant associations with age of psychosis onset either in female or in male subjects (data not shown).

General characteristics with respect to the TGFB1+ 869T/C polymorphism are provided in Table 3 . There was no significant association between the TGFB1 $+869 \mathrm{~T} / \mathrm{C}$

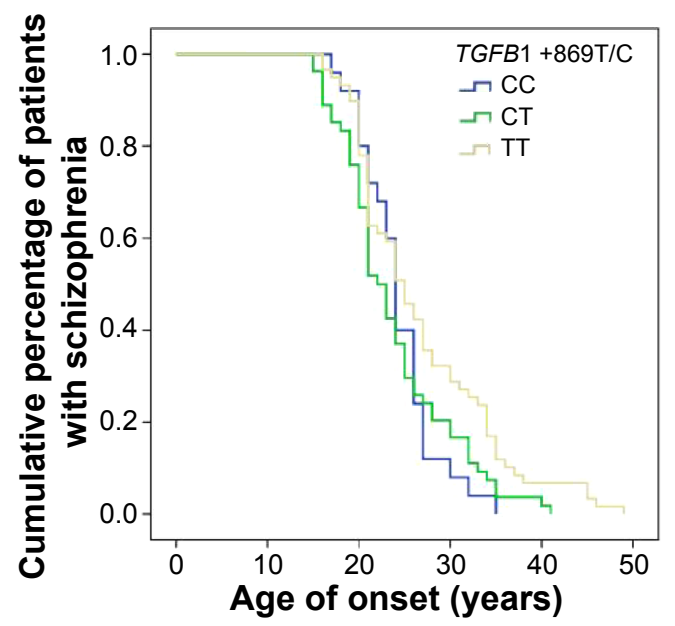

Figure 2 Kaplan-Meier survival plot of genotype-specific age of onset distribution curves with respect to the TGFBI $+869 \mathrm{~T} / \mathrm{C}$ polymorphism.

Notes: Long-rank test $\chi^{2}=6.54, d f=2, P=0.038$. polymorphism and demographic variables, basic clinical characteristics (number of previous episodes, illness duration, family history of schizophrenia, and chronic course of the disorder), or possible confounding factors (chlorpromazine equivalent, BMI, and pack-year index for cigarette smoking). Similarly, the $T G F B 1+915 \mathrm{G} / \mathrm{C}$ polymorphism was not associated with any of these variables (data not shown). There was no statistically significant difference between demographic and clinical variables among male and female patients with respect to the $T G F B 1+869 \mathrm{~T} / \mathrm{C}$ and $+915 \mathrm{G} / \mathrm{C}$ polymorphisms (data not shown).

All of the patients had been medicated on the day of the assessment. The mean duration of treatment was $12.24 \pm 12.24$ years. The majority of patients were treated with second-generation antipsychotic drugs (14.58\% olanzapine, $27.08 \%$ risperidone, $12.50 \%$ quetiapine, $21.87 \%$ clozapine, $11.45 \%$ ziprasidone, $2.08 \%$ aripiprazole, $2.08 \%$ sertindole), while the rest of the patients were treated with first-generation antipsychotics $(2.08 \%$ chlorpromazine, $1.04 \%$ perazine, $1.04 \%$ zuclopenthixol, $4.16 \%$ haloperidol). The mean value of daily chlorpromazine equivalent dose was $571.84 \pm 401.98 \mathrm{mg} /$ day $^{29}$

Correlations between TGF- $\beta$ level and clinical variables are shown in Table 4. TGF- $\beta$ serum level was not associated with illness duration, number of previous episodes, number of years of completed education, age, pack-year smoking index, BMI, or chlorpromazine equivalent dosage. Serum TGF- $\beta$ was not associated either with schizophrenia psychopathology or cognitive performance (Table 5). There was no difference between male and female patients with respect to age $(P=0.09)$, number of previous episodes $(P=0.56)$, BMI ( $P=0.25)$, pack-year index of cigarette smoking $(P=0.18)$, chlorpromazine equivalent dosage $(P=0.72)$, education level ( $P=0.17)$, number of years of completed education $(P=0.11)$, PANSS total score $(P=0.10)$, or any of the cognitive tests $(P>0.05)$. However, there was a difference in the age of onset (females $26.6 \pm 7.8$ years, males $23.12 \pm 4.44$ years, $P=0.016$ ), 
Table 3 General demographic and clinical characteristics of schizophrenia patients with respect to the TGFBI +869T/C polymorphism

\begin{tabular}{|c|c|c|c|c|}
\hline \multirow{2}{*}{$\begin{array}{l}\text { Clinical and demographic } \\
\text { variables }\end{array}$} & \multicolumn{3}{|c|}{ TGFBI +869T/C genotype } & \multirow[t]{2}{*}{$P$-value ${ }^{a}$} \\
\hline & $\mathrm{CC}$ & CT & TT & \\
\hline Age (years) & $38.50 \pm 19.55$ & $33.10 \pm 9.67$ & $41.38 \pm 11.29$ & 0.59 \\
\hline Female (\%) & 71.43 & 56.90 & 59.68 & $0.42^{\mathrm{b}}$ \\
\hline Education (\%) & & & & $0.91^{\mathrm{b}}$ \\
\hline Primary & 0 & 7.69 & 9.52 & \\
\hline Vocational & 20.00 & 23.08 & 16.67 & \\
\hline Secondary & 60.00 & 48.72 & 50.00 & \\
\hline Higher & 20.00 & $20.5 I$ & 21.43 & \\
\hline Education (years) & $14.17 \pm 3.37$ & $12.80 \pm 26.16$ & $13.85 \pm 3.00$ & 0.69 \\
\hline Age of onset (years) & $29.50 \pm 9.40$ & $22.80 \pm 3.26$ & $26.54 \pm 8.81$ & 0.12 \\
\hline Disease duration (years) & $9.00 \pm 10.95$ & $10.30 \pm 8.96$ & $14.85 \pm 8.68$ & 0.71 \\
\hline Number of previous episodes & $4.50 \pm 3.27$ & $4.50 \pm 3.41$ & $5.46 \pm 4.18$ & 0.78 \\
\hline Chlorpromazine equivalent & $391.67 \pm 251.16$ & $618.50 \pm 436.18$ & $617.95 \pm 498.44$ & 0.29 \\
\hline Body mass index $\left(\mathrm{kg} / \mathrm{m}^{2}\right)$ & $24.89 \pm 2.99$ & $25.14 \pm 4.37$ & $28.72 \pm 9.13$ & 0.58 \\
\hline Pack-year smoking index & $7.28 \pm 14.82$ & $6.34 \pm 12.13$ & $14.35 \pm 18.79$ & 0.19 \\
\hline
\end{tabular}

Notes: ${ }^{a}$ Kruskal-Wallis test; ${ }^{\mathrm{b}} \chi^{2}$ test. Mean and standard deviation values are presented. Pack-year index is the number of cigarettes packs per month $\times$ number of years smoking.

which is one of the most commonly described aspects of sex dimorphism in schizophrenia. There was no significant difference in TGF- $\beta$ level between female and male patients (median \pm interquartile range: $44.15 \pm 13.70 \mathrm{ng} / \mathrm{mL}$, $42.85 \pm 14.10 \mathrm{ng} / \mathrm{mL}$, respectively, $P=0.47$ ). Additionally, the $T G F B 1+869 \mathrm{~T} / \mathrm{C}$ polymorphism did not influence TGF- $\beta$ level either in female $(P=0.78)$ or in male patients $(P=0.19)$. Similarly, the $T G F B 1+915 \mathrm{G} / \mathrm{C}$ polymorphism did not influence TGF- $\beta$ level either in female $(P=0.65)$ or in male patients $(P=0.14)$.

There was no significant difference in psychopathological manifestation assessed using PANSS, SAPS, and SANS with respect to the $T G F B 1+869 \mathrm{~T} / \mathrm{C}$ and $+915 \mathrm{G} / \mathrm{C}$ polymorphisms $(P>0.05)$. There was no significant association between $T G F B 1+915 \mathrm{G} / \mathrm{C}$ polymorphism and cognitive functioning in schizophrenia (data not shown); however, subjects carrying the $+869 \mathrm{~T}$ allele performed worse in comparison

Table 4 Correlations between TGF- $\beta$ level and clinical variables in patients with schizophrenia

\begin{tabular}{lll}
\hline Clinical variables & \multicolumn{2}{l}{ TGF- $\beta$ level } \\
\cline { 2 - 3 } & Rho & P-value $^{\mathbf{a}}$ \\
\hline Disease duration (years) & -0.42 & 0.72 \\
Age (years) & -0.13 & 0.28 \\
Number of previous episodes & -0.03 & 0.82 \\
Number of years of completed education (years) & 0.55 & 0.75 \\
Pack year smoking index & -0.08 & 0.55 \\
Body mass index (kg/m $\left.\mathrm{m}^{2}\right)$ & 0.20 & 0.16 \\
Chlorpromazine equivalent & -0.03 & 0.84 \\
\hline
\end{tabular}

Notes: ${ }^{2}$ Spearman's rank correlations. Pack-year index is the number of cigarettes packs per month $\times$ number of years smoking. with $+869 \mathrm{CC}$ homozygotes on Stroop test $(P=0.02)$, Verbal Fluency task (F words) $(P=0.03)$, and on Digit Symbol Coding task $(P=0.06)$.

After adjustment for possible confounding factors, such as age, education level, illness duration, total PANSS score, BMI, smoking, chlorpromazine equivalent, and TGF- $\beta$ serum level, there was a statistically significant difference in cognitive performance on Digit Symbol Coding task with respect to the $T G F B 1+869 \mathrm{~T} / \mathrm{C}$ polymorphism among female schizophrenia patients $(\beta=-0.57, t=-2.78$, $P=0.02)$.

\section{Discussion}

There are numerous studies showing the influence of the immune system deregulation on the risk of schizophrenia and its clinical manifestation. ${ }^{30,31}$ However, the association between the TGFB1 gene polymorphisms and TGF- $\beta$ level with schizophrenia course and symptomatology, together with cognitive functioning, has not been investigated so far.

In our study, we showed that TGF- $\beta$ level was significantly higher in patients with schizophrenia than in healthy control subjects, even after covarying for age and sex. The majority of previous studies on medicated and drug-naïve first-episode patients have also shown higher TGF- $\beta$ levels in schizophrenia subjects in comparison to healthy controls, ${ }^{32-34}$ with the exception of one study that failed to show this association. $^{35}$

Studies, which have attempted to establish the relationship between the TGFB1 gene polymorphisms and TGF- $\beta$ level, have yielded ambiguous results. ${ }^{36,37}$ In the present study, we 
Table 5 Psychopathological manifestation and cognitive performance with respect to the TGFBI +869T/C polymorphism

\begin{tabular}{|c|c|c|c|c|c|}
\hline \multirow{2}{*}{$\begin{array}{l}\text { Psychopathological } \\
\text { symptoms and cognitive } \\
\text { performance }\end{array}$} & \multicolumn{3}{|c|}{ TGFBI $+869 \mathrm{~T} / \mathrm{C}$ carriers } & \multicolumn{2}{|c|}{ TGF- $\beta$ serum level } \\
\hline & CC & CT and TT & $P$-value ${ }^{a}$ & Rho & $P$-value \\
\hline \multicolumn{6}{|l|}{ Psychopathology } \\
\hline PANSS - positive symptoms & $19,17.71 \pm 5.63$ & $20,20.11 \pm 7.26$ & 0.41 & $<0.01$ & 0.92 \\
\hline PANSS - negative symptoms & $20.50,21.50 \pm 8.05$ & $23,23.27 \pm 8.24$ & 0.52 & $<0.01$ & 0.96 \\
\hline PANSS - general psychopathology & $39.50,39.43 \pm 8.16$ & $39,40.76 \pm 11.10$ & 0.95 & 0.07 & 0.57 \\
\hline PANSS - total score & $84,78.64 \pm 17.56$ & $81,84.14 \pm 23.88$ & 0.69 & 0.01 & 0.92 \\
\hline PANSS - depression item score & $I, 1.86 \pm 1.23$ & 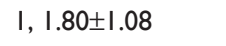 & 0.91 & 0.11 & 0.35 \\
\hline SAPS & $29.50,29.86 \pm 18.58$ & $30,31.24 \pm 20.56$ & 0.78 & 0.07 & 0.55 \\
\hline SANS & $44,38.14 \pm 19.28$ & $37,40.82 \pm 21.77$ & 0.70 & $<0.01$ & 0.99 \\
\hline \multicolumn{6}{|l|}{ Cognitive tasks } \\
\hline Trail making test, part $\mathrm{A}$ & $36,38 \pm 15.24$ & $42,46.57 \pm 20.40$ & 0.16 & -0.13 & 0.30 \\
\hline Trail making test, part B & $100.50,103.8 \pm 55.7$ & $110,143.4 \pm 104.4$ & 0.16 & -0.19 & 0.13 \\
\hline Stroop, congruent & $32,37.47 \pm I I .13$ & $41,45.39 \pm 19.56$ & 0.02 & 0.01 & 0.95 \\
\hline Stroop, incongruent & $70,78.47 \pm 47.20$ & $76,82.33 \pm 33.74$ & 0.29 & 0.16 & 0.18 \\
\hline RAVLT, immediate recall Ist-5th & $33.50,35.72 \pm 11.76$ & $36,35.86 \pm 10.90$ & 0.92 & $<0.01$ & 0.93 \\
\hline RAVLT, interference & $7.50,6.88 \pm 3.26$ & $7,7.39 \pm 2.82$ & 0.74 & -0.01 & 0.91 \\
\hline RAVLT, delayed recall & $6,6.00 \pm 3.33$ & $7,6.50 \pm 2.96$ & 0.89 & -0.06 & 0.61 \\
\hline RAVLT, recognition & II, $9.69 \pm 4.04$ & $I 0,9.4 I \pm 3.94$ & 0.72 & 0.08 & 0.52 \\
\hline Verbal fluency, F words & $8,8.47 \pm 3.24$ & $6,6.49 \pm 3.76$ & 0.03 & 0.07 & 0.56 \\
\hline Verbal fluency, A words & $9,7.67 \pm 10.09$ & $5,6.25 \pm 3.62$ & 0.13 & 0.07 & 0.59 \\
\hline Verbal fluency, S words & $9,9.53 \pm 3.64$ & $8,8.00 \pm 3.74$ & 0.44 & -0.09 & 0.46 \\
\hline Verbal fluency, supermarket & $16,17.20 \pm 6.53$ & $15,16.06 \pm 6.83$ & 0.80 & 0.09 & 0.47 \\
\hline Forward Digit Span & $6,5.82 \pm 1.63$ & $6,6.11 \pm 1.89$ & 0.67 & -0.01 & 0.91 \\
\hline Backward Digit Span & $5,1.33 \pm 1.33$ & $5,5.04 \pm 2.10$ & 0.78 & $<0.01$ & 0.95 \\
\hline Digit Symbol Coding & $39,42.18 \pm 13.11$ & $35,35.05 \pm 14.00$ & $0.06 *$ & -0.01 & 0.98 \\
\hline Similarities & $17,16.67 \pm 4.24$ & $15.5,15.88 \pm 5.34$ & 0.92 & 0.23 & 0.06 \\
\hline
\end{tabular}

Notes: aMann-Whitney U-test; 'Spearman's rank correlations. Median, mean and standard deviation values are presented. Significant associations have been marked in bold characters ( $P$-value $<0.05$, two-tailed) and trend level association is indicated by bold characters marked with* ( $P$-value $<0.1$, two-tailed).

Abbreviations: PANSS, Positive and Negative Syndrome Scale; RAVLT, Rey Auditory Verbal Learning Test; SAPS, Scale for Assessment of Positive Symptoms; SANS, Scale for Assessment of Negative Symptoms.

found that the $T G F B 1+869 \mathrm{~T} / \mathrm{C}$ and $+915 \mathrm{G} / \mathrm{C}$ polymorphisms are not associated with TGF- $\beta$ level in schizophrenia patients. However, we revealed that the TGFB1 $+869 \mathrm{~T} / \mathrm{C}$ but not the $T G F B 1+915 \mathrm{G} / \mathrm{C}$ polymorphism is associated with TGF- $\beta$ level in healthy controls. The explanation of a differential contribution of the TGFB1 $+869 \mathrm{~T} / \mathrm{C}$ polymorphism in schizophrenia patients and healthy controls would originate from a complex regulation of gene expression within the TGF- $\beta$ signaling pathway. In the recent study by Umeda-Yano et a ${ }^{10}$ it was found that overexpression of the ZNF804A gene may lead to altered expression of genes encoding proteins acting on the TGF- $\beta$ signaling pathway. Notably, large data sets indicate that the SNP (rs1344706) in the ZNF804A gene is one of the top genetic variants associated with schizophrenia. ${ }^{38}$

In our study, we showed no association between TGF- $\beta$ levels and clinical variables, including current (PANSS, SANS, SAPS) or lifetime (OPCRIT) psychopathological manifestation of schizophrenia. Other researchers have also found no correlations with current clinical status as assessed by the Brief
Psychiatric Rating Scale ${ }^{30}$ or PANSS. ${ }^{39}$ However, the analysis of counter-regulatory cytokines ratio, such as IFN- $\gamma /$ TGF- $\beta$ ratio, has shown a weak negative correlation with negative symptoms and general psychopathology subscales of PANSS, ${ }^{31}$ as well as the total PANSS score. ${ }^{31,32}$ Additionally, a weak negative correlation has been found between the IL-17/TGF- $\beta$ ratio and the negative and general psychopathology PANSS subscales. ${ }^{32}$

We found no significant association between the TGFB1 gene polymorphisms and schizophrenia current and life-time symptomatology, or variables associated with course of the disorder. However, we found that the TGFB1 +869T/C polymorphism may predict age of psychosis onset in female patients. Indeed, females with the $+869 \mathrm{TT}$ and $+869 \mathrm{CT}$ genotypes had significantly later age of psychosis onset in comparison with females with the $+869 \mathrm{CC}$ genotype. These findings are in agreement with the results that were previously published by our group. ${ }^{14} \mathrm{We}$ found that the risk of schizophrenia is more than twofold higher in the $+869 \mathrm{~T}$ allele carriers in comparison with those with the $+869 \mathrm{CC}$ genotype. When we 
conducted a separate analysis of male and female subjects, we found that this association was significant in females, while in males it reached a trend toward significant difference. Several lines of evidence support strong heritability of age at onset in schizophrenia. ${ }^{40-42}$ Moreover, there is a plethora of studies linking SNPs to age of psychosis onset. Although the majority of these studies show that the risk allele for schizophrenia is simultaneously associated with earlier age of psychosis onset, there is a considerable number of studies linking the risk polymorphic variant to later age of psychosis onset. ${ }^{43-45}$

Cognitive impairment serves as the core component of schizophrenia symptomatology that accounts for poor functional outcome. ${ }^{46,47}$ Although the efficacy of current pharmacological strategies with respect to psychotic symptoms seems to be sufficient, their impact on cognition leaves much to be desired. ${ }^{48}$ Therefore, our understanding of biological mechanisms underlying cognitive dysfunction in schizophrenia patients appears to be a major challenge for current psychiatric research. However, immune alterations are sparsely addressed in studies focused on cognitive impairment in schizophrenia patients. There is evidence that C-reactive protein (CRP) level negatively correlates with cognitive functioning. ${ }^{49,50}$ It has also been found that this relationship is augmented by Herpes Simplex Virus- $1^{51,52}$ and cytomegalovirus seropositivity. ${ }^{52}$ Additionally, the leukemia inhibitory factor gene polymorphism has been associated with deterioration in working memory function in patients with schizophrenia. ${ }^{53}$ With respect to cytokine serum levels in schizophrenia, cognitive impairment has been associated with higher IL- $6^{50}$ and IL- $18^{54}$ as well as lower IL- $2^{55}$ levels.

Our study is the first to address cognitive correlates of TGF- $\beta$ level and the TGFB1 gene polymorphisms in schizophrenia. We found no association between TGF- $\beta$ level and cognition; however, our findings suggest that the $T G F B 1+869 \mathrm{~T} / \mathrm{C}$ polymorphism is associated with cognitive functioning in schizophrenia. In our study, the $+869 \mathrm{~T}$ allele carriers performed worse on tests measuring processing speed (Digit Symbol Coding task, Stroop congruent task) and verbal fluency ( $F$ words). Interestingly, after adjustment for potential confounders, such as age, education level, illness duration, total PANSS score, BMI, smoking, chlorpromazine equivalent, and TGF- $\beta$ serum level, the +869 T allele carriers scored significantly lower only on Digit Symbol Coding task in comparison with the $+869 \mathrm{CC}$ homozygotes, among female patients. The meta-analysis of neuropsychological measures in schizophrenia revealed that Digit Symbol Coding task shows significantly larger effect in differentiating schizophrenia and healthy subjects in comparison with other cognitive measures including verbal memory, executive functioning, or working memory tasks.$^{56}$ Digit Symbol Coding task is considered to be a cognitive endophenotype - a measurable biomarker that is correlated with an illness due to shared underlying genetic influences. It has been shown to have high heritability and stable trait-like qualities, and is associated with prognosis, as well as functional outcome among patients with schizophrenia. ${ }^{56}$

Interestingly, studies investigating the polymorphism in the ZNF804A gene (rs1344706), known to upregulate genes implicated in the TGF- $\beta$ signaling, ${ }^{10}$ have shown its correlation with several domains of cognitive performance including episodic and working memory, executive functions, verbal learning, and recall. ${ }^{57-61}$ Most interestingly, the ZNF804A gene polymorphism (rs 1344706) has been found to predict poorer executive control of attention in schizophrenia, overlapping partially with the results of our study.$^{60}$ Additionally, there is one study that established a susceptibility link between the TGFB1 +869T/C polymorphism and Alzheimer's disease, ${ }^{18}$ suggesting that cognitive decline both in schizophrenia and dementia may be partially influenced by the same set of genes associated with the immune system. ${ }^{62,63}$

Our results, showing the association of the $T G F B 1+869 \mathrm{~T} / \mathrm{C}$ polymorphism with age of onset and cognitive performance in female patients, point to the list of sex differences in schizophrenia (for review see ${ }^{64,65}$ ). Indeed, female patients with schizophrenia tend to have later age of psychosis onset; ${ }^{66}$ more affective ${ }^{67}$ and less negative symptoms; ${ }^{68}$ as well as less severe course of the disorder. ${ }^{69}$ The presence of sex differences in schizophrenia has been attributed to neuroprotective and antidopaminergic properties of estradiol. ${ }^{65,69,70}$ To support hormonal underpinnings, it has been found that there is a fluctuation in the severity of psychopathological manifestation across the menstruation cycle, with deterioration of symptomatology during low-estrogen phases. ${ }^{71}$ Furthermore, chronic psychosis is prone to improvement during pregnancy. ${ }^{72}$ Finally, low-estrogen lifespan phases including perimenstrual phase of the menstrual cycle, postmenopause, and the period after abortion are characterized by higher susceptibility to psychosis. ${ }^{71}$ Interestingly, it has been found that females with first-episode psychosis are characterized by significantly higher TGF- $\beta$ levels. ${ }^{33}$ There is also a crosstalk between TGF- $\beta$ and estradiol. It has been found that estradiol increases the production of TGF- $\beta$ in cortical and hypothalamic astrocytes. ${ }^{73,74}$ On the other hand, TGF- $\beta$ may stimulate the production of estradiol via promotion of the basal secretion of follicle-stimulating hormone. ${ }^{75}$ However, these interactions are yet to be investigated in schizophrenia patients. 
Our results should be interpreted with caution due to limitations that require further discussion. Firstly, it should be noted that our sample size was limited; however, it is one of the largest studies analyzing serum cytokine levels with respect to cognitive functioning in schizophrenia. ${ }^{50,54,55,76} \mathrm{Sec}-$ ondly, all our patients were medicated, while the association of TGF- $\beta$ level with cognitive functioning in unmedicated first-episode schizophrenia patients would be much more reliable. However, it should be noted that we found no association between TGF- $\beta$ level and daily chlorpromazine equivalent dose, and previous studies have shown higher TGF- $\beta$ levels in both drug-naïve and medicated schizophrenia patients in comparison to controls. ${ }^{32}$ Additionally, our study assessed cognitive functions only at one point while, in the future, longitudinal design might bring insight into how changes in antipsychotic treatment are translated into changes in TGF- $\beta$ level and cognitive performance with time, especially in first-episode patients. Moreover, in our study, we did not assess menstrual cycle stage in female participants. This should be included in the future studies' protocols, as this information may shed more light on the reciprocal interaction between estrogen and TGF- $\beta$ levels in the brain, possibly playing a role in the sex dimorphism of schizophrenia. Finally, future studies should look into the $T G F B 1+869$ T/C polymorphism together with TGF- $\beta$ level on all indices associated with metabolic syndrome, including hypertension and glucose intolerance, especially due to their high prevalence in schizophrenia and their influence on cognition in this group of patients.

\section{Acknowledgments}

We are deeply grateful to all patients and healthy controls participating in this study. We thank Anna Partyka for the genotyping. This work was supported by research grant "IL-2, IL-6, IFN-gamma and TGF-beta gene polymorphism in patients with schizophrenia" awarded by Ministry of Science and Higher Education, Grant Number N N402 465237.

\section{Disclosure}

The authors report no conflicts of interest in this work.

\section{References}

1. Potvin S, Stip E, Sepehry AA, Gendron A, Bah R, Kouassi E. Inflammatory cytokine alterations in schizophrenia: a systematic quantitative review. Biol Psychiatry. 2008;63(8):801-808.

2. Kirkpatrick B, Miller BJ. Inflammation and schizophrenia. Schizophr Bull. 2013;39(6):1174-1179.

3. Zakharyan R, Boyajyan A. Inflammatory cytokine network in schizophrenia. World J Biol Psychiatry. 2014;15(3):174-187.
4. Miller BJ, Buckley P, Seabolt W, Mellor A, Kirkpatrick B. Metaanalysis of cytokine alterations in schizophrenia: clinical status and antipsychotic effects. Biol Psychiatry. 2011;70(7):663-671.

5. Li MO, Wan YY, Sanjabi S, Robertson AK, Flavell RA. Transforming growth factor-beta regulation of immune responses. Anпu Rev Immunol. 2006;24:99-146.

6. Cai J, Schleidt S, Pelta-Heller J, Hutchings D, Cannarsa G, Iacovitti L. BMP and TGF- $\beta$ pathway mediators are critical upstream regulators of Wnt signaling during midbrain dopamine differentiation in human pluripotent stem cells. Dev Biol. 2013;376(1):62-73.

7. Krieglstein K, Suter-Crazzolara C, Fischer WH, Unsicker K. TGF-beta superfamily members promote survival of midbrain dopaminergic neurons and protect them against MPP + toxicity. EMBO J. 1995;14(4):736-742.

8. Poulsen KT, Armanini MP, Klein RD, Hynes MA, Phillips HS, Rosenthal A. TGF beta 2 and TGF beta 3 are potent survival factors for midbrain dopaminergic neurons. Neuron. 1994;13(5):1245-1252.

9. Jia P, Wang L, Meltzer HY, Zhao Z. Common variants conferring risk of schizophrenia: a pathway analysis of GWAS data. Schizophr Res. 2010;122(1-3):38-42.

10. Umeda-Yano $\mathrm{S}$, Hashimoto R, Yamamori $\mathrm{H}$, et al. The regulation of gene expression involved in TGF- $\beta$ signaling by ZNF804A, a risk gene for schizophrenia. Schizophr Res. 2013;146(1-3):273-278.

11. Benes FM, Lim B, Matzilevich D, Walsh JP, Subburaju S, Minns M. Regulation of the GABA cell phenotype in hippocampus of schizophrenics and bipolars. Proc Natl Acad Sci U S A. 2007;104(24): 10164-10169.

12. AwadMR, El-Gamel A, Hasleton P, TurnerDM, SinnottPJ, Hutchinson IV. Genotypic variation in the transforming growth factor-betal gene: association with transforming growth factor-betal production, fibrotic lung disease, and graft fibrosis after lung transplantation. Transplantation. 1998;66(8):1014-1020.

13. Yamada Y, Miyauchi A, Goto J, et al. Association of a polymorphism of the transforming growth factor-betal gene with genetic susceptibility to osteoporosis in postmenopausal Japanese women. J Bone Miner Res. 1998;13(10):1569-1576.

14. Frydecka D, Misiak B, Beszlej JA, et al. Genetic variants in transforming growth factor- $\beta$ gene (TGFB1) affect susceptibility to schizophrenia. Mol Biol Rep. 2013;40(10):5607-5614.

15. Loeys BL, Chen J, Neptune ER, et al. A syndrome of altered cardiovascular, craniofacial, neurocognitive and skeletal development caused by mutations in TGFBR1 or TGFBR2. Nat Genet. 2005;37(3):275-281.

16. Ongali B, Nicolakakis N, Lecrux C, et al. Transgenic mice overexpressing APP and transforming growth factor-betal feature cognitive and vascular hallmarks of Alzheimer's disease. The Am J Pathol. 2010; 177(6):3071-3080.

17. Nicolakakis N, Aboulkassim T, Aliaga A, Tong XK, Rosa-Neto P, Hamel E. Intact memory in TGF- $\beta 1$ transgenic mice featuring chronic cerebrovascular deficit: recovery with pioglitazone. J Cereb Blood Flow Metab. 2011;31(1):200-211.

18. Arosio B, Bergamaschini L, Galimberti L, et al. $+10 \mathrm{~T} / \mathrm{C}$ polymorphisms in the gene of transforming growth factor-betal are associated with neurodegeneration and its clinical evolution. Mech Ageing Dev. 2007; 128(10):553-557.

19. McGuffin P, Farmer A, Harvey I. A polydiagnostic application of operational criteria in studies of psychotic illness. Development and reliability of the OPCRIT system. Arch Gen Psychiatry. 1991;48(8): 764-770.

20. Kay SR, Fiszbein A, Opler LA. The positive and negative syndrome scale (PANSS) for schizophrenia. Schizophr Bull. 1987;13(2):261-276.

21. Andreasen NC. Methods for assessing positive and negative symptoms. Mod Probl Pharmacopsychiatry. 1990;24:73-88.

22. Andreasen NC. Negative symptoms in schizophrenia. Definition and reliability. Arch Gen Psychiatry. 1982;39(7):784-788.

23. Rey A. L'examen psychologique dans les cas d'encéphalopathie traumatique. Les problèmes [The psychological examination in cases of traumatic encephalopathy. Problems]. Archives de Psychologie. 1941;28: 215-228. French. 
24. Reitan RM. The relation of the trail making test to organic brain damage. J Consult Psychol. 1955;19(5):393-394.

25. Benton AL. Differential behavioural effects in frontal lobe disease. Neuropsychologia. 1968;6:53-60.

26. Kessler J, Denzler P, Markowitsch HJ. Demenztest [Test for dementia]. Weinheim: Beltz Test GmbH; 1988. German.

27. Jensen AR. Scoring the Stroop test. Acta Psychol (Amst). 1965;24(5): 398-408

28. Brzeziński J, Hornowska E. Skala Inteligencji Wechslera dla Dorostych. Wersja Zrewidowana. Polska Adaptacja WAIS-R (PL) [Scale of the Wechsler Adult Intelligence. The revised version. Polish adaptation WAIS-R (PL)]. Warszawa: Wydawnictwo Naukowe PWN; 1996. Polish.

29. Woods SW. Chlorpromazine equivalent doses for the newer atypical antipsychotics. J Clin Psychiatry. 2003;64(6):663-667.

30. Na KS, Jung HY, Kim YK. The role of pro-inflammatory cytokines in the neuroinflammation and neurogenesis of schizophrenia. Prog Neuropsychopharmacol Biol Psychiatry. 2014;48:277-286.

31. Jones AL, Mowry BJ, Pender MP, Greer JM. Immune dysregulation and self-reactivity in schizophrenia: do some cases of schizophrenia have an autoimmune basis? Immunol Cell Biol. 2005;83(1):9-17.

32. Kim YK, Myint AM, Lee BH, et al. Th1, Th2 and Th3 cytokine alteration in schizophrenia. Prog Neuropsychopharmacol Biol Psychiatry. 2004;28(7):1129-1134.

33. Borovcanin M, Jovanovic I, Radosavljevic G, et al. Elevated serum level of type-2 cytokine and low IL-17 in first episode psychosis and schizophrenia in relapse. J Psychiatr Res. 2012;46(11):1421-1426.

34. Borovcanin M, Jovanovic I, Radosavljevic G, et al. Antipsychotics can modulate the cytokine profile in schizophrenia: attenuation of the type-2 inflammatory response. Schizophr Res. 2013;147(1): 103-109.

35. Lin CC, Chang CM, Chang PY, Huang TL. Increased interleukin-6 level in Taiwanese schizophrenic patients. Chang Gung Med J. 2011;34(4): 375-381.

36. Hutchinson IV, Turner DM, Sankaran D, Awad MR, Sinnott PJ. Influence of cytokine genotypes on allograft rejection. Transplant Proc. 1998;30(3):862-863.

37. Han IB, Ropper AE, Jeon YJ, et al. Association of transforming growth factor-beta1 gene polymorphism with genetic susceptibility to ossification of the posterior longitudinal ligament in Korean patients. Genet Mol Res. 2013;12(4):4807-4816.

38. O'Donovan MC, Craddock N, Norton N, et al. Identification of loci associated with schizophrenia by genome-wide association and follow-up. Nat Genet. 2008;40(9):1053-1055.

39. Kim YK, Myint AM, Verkerk R, Scharpe S, Steinbusch H, Leonard B. Cytokine changes and tryptophan metabolites in medication-naive and medication-free schizophrenic patients. Neuropsychobiology. 2009; 59(2):123-129.

40. Hare E, Glahn DC, Dassori A, et al. Heritability of age of onset of psychosis in schizophrenia. Am J Med Genet B Neuropsychiatr Genet. 2010;153B(1):298-302.

41. Vassos E, Sham PC, Cai G, et al. Correlation and familial aggregation of dimensions of psychosis in affected sibling pairs from China. $\mathrm{Br} \mathrm{J}$ Psychiatry. 2008;193(4):305-310.

42. Husted JA, Greenwood CM, Bassett AS. Heritability of schizophrenia and major affective disorder as a function of age, in the presence of strong cohort effects. Eur Arch Psychiatry Clin Neurosci. 2006;256(4): 222-229.

43. Voisey J, Swagell CD, Hughes IP, Lawford BR, Young RM, Morris CP. A novel DRD2 single-nucleotide polymorphism associated with schizophrenia predicts age of onset: HapMap tag-single-nucleotide polymorphism analysis. Genet Test Mol Biomarkers. 2012;16(2): 77-81.

44. Hanninen K, Katila H, Saarela M, et al. Interleukin-1 beta gene polymorphism and its interactions with neuregulin-1 gene polymorphism are associated with schizophrenia. Eur Arch Psychiatry Clin Neurosci. 2008;258(1):10-15.
45. Sacchetti E, Bocchio-Chiavetto L, Valsecchi P, et al. G308A tumor necrosis factor alpha functional polymorphism and schizophrenia risk: meta-analysis plus association study. Brain Behav Immun. 2007;21(4):450-457.

46. Keefe RS, Harvey PD. Cognitive impairment in schizophrenia. Handb Exp Pharmacol. 2012;(213):11-37.

47. Barch DM, Ceaser A. Cognition in schizophrenia: core psychological and neural mechanisms. Trends Cogn Sci. 2012;16(1):27-34.

48. Ibrahim HM, Tamminga CA. Treating impaired cognition in schizophrenia. Curr Pharm Biotechnol. 2012;13(8):1587-1594.

49. Dickerson F, Stallings C, Origoni A, et al. C-reactive protein is elevated in schizophrenia. Schizophr Res. 2013;143(1):198-202.

50. Frydecka D, Misiak B, Pawlak-Adamska E, et al. Interleukin-6: the missing element of the neurocognitive deterioration in schizophrenia? The focus on genetic underpinnings, cognitive impairment and clinical manifestation. Eur Arch Psychiatry Clin Neurosci. Epub 2014 Sep 12.

51. Dickerson F, Stallings C, Origoni A, Vaughan C, Khushalani S, Yolken R. Additive effects of elevated C-reactive protein and exposure to Herpes Simplex Virus type 1 on cognitive impairment in individuals with schizophrenia. Schizophr Res. 2012;134(1):83-88.

52. Shirts BH, Prasad KM, Pogue-Geile MF, Dickerson F, Yolken RH, Nimgaonkar VL. Antibodies to cytomegalovirus and Herpes Simplex Virus 1 associated with cognitive function in schizophrenia. Schizophr Res. 2008;106(2-3):268-274.

53. Okahisa Y, Ujike H, Kunugi $H$, et al. Leukemia inhibitory factor gene is associated with schizophrenia and working memory function. Prog Neuropsychopharmacol Biol Psychiatry. 2010;34(1):172-176.

54. Zhang XY, Tang W, Xiu MH, et al. Interleukin 18 and cognitive impairment in first episode and drug naïve schizophrenia versus healthy controls. Brain Behav Immun. 2013;32:105-111.

55. Asevedo E, Rizzo LB, Gadelha A, et al. Peripheral interleukin-2 level is associated with negative symptoms and cognitive performance in schizophrenia. Physiol Behav. 2014;129:194-198.

56. Dickinson D, Ramsey ME, Gold JM. Overlooking the obvious: a metaanalytic comparison of digit symbol coding tasks and other cognitive measures in schizophrenia. Arch Gen Psychiatry. 2007;64(5):532-542.

57. Van Den Bossche MJ, Docx L, Morrens M, et al. Less cognitive and neurological deficits in schizophrenia patients carrying risk variant in ZNF804A. Neuropsychobiology. 2012;66(3):158-166.

58. Walters JT, Corvin A, Owen MJ, et al. Psychosis susceptibility gene ZNF804A and cognitive performance in schizophrenia. Arch Gen Psychiatry. 2010;67(7):692-700.

59. Nicodemus KK, Elvevåg B, Foltz PW, Rosenstein M, Diaz-Asper C, Weinberger DR. Category fluency, latent semantic analysis and schizophrenia: a candidate gene approach. Cortex. 2014;55:182-191.

60. Balog Z, Kiss I, Kéri S. ZNF804A may be associated with executive control of attention. Genes Brain Behav. 2011;10(2):223-227.

61. Chen M, Xu Z, Zhai J, et al. Evidence of IQ-modulated association between ZNF804A gene polymorphism and cognitive function in schizophrenia patients. Neuropsychopharmacology. 2012;37(7):1572-1578.

62. Eriksson UK, Pedersen NL, Reynolds CA, et al. Associations of gene sequence variation and serum levels of C-reactive protein and interleukin-6 with Alzheimer's disease and dementia. J Alzheimers Dis. 2011;23(2):361-369.

63. Miller BJ, Culpepper N, Rapaport MH. C-reactive protein levels in schizophrenia: a review and meta-analysis. Clin Schizophr Relat Psychoses. 2014;7(4):223-230.

64. Abel KM, Drake R, Goldstein JM. Sex differences in schizophrenia. Int Rev Psychiatry. 2010;22(5):417-428.

65. Markham JA. Sex steroids and schizophrenia. Rev Endocr Metab Disord. 2012;13(3):187-207.

66. Aleman A, Kahn RS, Selten JP. Sex differences in the risk of schizophrenia: evidence from meta-analysis. Arch Gen Psychiatry. 2003;60(6):565-571.

67. Koster A, Lajer M, Lindhardt A, Rosenbaum B. Gender differences in first episode psychosis. Soc Psychiatry Psychiatr Epidemiol. 2008; 43(12):940-946. 
68. Thorup A, Petersen L, Jeppesen P, et al. Gender differences in young adults with first-episode schizophrenia spectrum disorders at baseline in the Danish OPUS study. J Nerv Ment Dis. 2007;195(5): 396-405.

69. Seeman MV, Lang M. The role of estrogens in schizophrenia gender differences. Schizophr Bull. 1990;16(2):185-194.

70. Dluzen DE. Neuroprotective effects of estrogen upon the nigrostriatal dopaminergic system. J Neurocytol. 2000;29(5-6):387-399.

71. Wu YC, Hill RA, Gogos A, van den Buuse M. Sex differences and the role of estrogen in animal models of schizophrenia: interaction with BDNF. Neuroscience. 2013;239:67-83.

72. McNeil TF, Kaij L, Malmquist-Larsson A. Women with nonorganic psychosis: factors associated with pregnancy's effect on mental health. Acta Psychiatr Scand. 1984;70(3):209-219.
73. Dhandapani KM, Wade FM, Mahesh VB, Brann DW. Astrocyte-derived transforming growth factor-\{beta\} mediates the neuroprotective effects of 17 \{beta\}-estradiol: involvement of nonclassical genomic signaling pathways. Endocrinology. 2005;146(6):2749-2759.

74. Buchanan CD, Mahesh VB, Brann DW. Estrogen-astrocyte-luteinizing hormone-releasing hormone signaling: a role for transforming growth factor-beta(1). Biol Reprod. 2000;62(6):1710-1721.

75. Ying SY. Inhibins, activins, and follistatins: gonadal proteins modulating the secretion of follicle-stimulating hormone. Endocr Rev. 1988;9(2): 267-293.

76. Lv MH, Tan YL, Yan SX, et al. Decreased serum TNF-alpha levels in chronic schizophrenia patients on long-term antipsychotics: correlation with psychopathology and cognition. Psychopharmacology (Berl). Epub 2014 Jun 24.

\section{Publish your work in this journal}

Neuropsychiatric Disease and Treatment is an international, peerreviewed journal of clinical therapeutics and pharmacology focusing on concise rapid reporting of clinical or pre-clinical studies on a range of neuropsychiatric and neurological disorders. This journal is indexed on PubMed Central, the 'PsycINFO' database and CAS, and is the official journal of The International Neuropsychiatric Association (INA). The manuscript management system is completely online and includes a very quick and fair peer-review system, which is all easy to use. Visit http://www.dovepress.com/testimonials.php to read real quotes from published authors.

Submit your manuscript here: http://www.dovepress.com/neuropsychiatric-disease-and-treatment-journal 